УДК 551.521.3(571.56)

ГЕЛИОЦИКЛИЧЕСКИЕ МОДУЛЯЦИИ ИЗМЕНЧИВОСТИ ПРИРОДНО-КЛИМАТИЧЕСКИХ И ИНЖЕНЕРНО-ГЕОЛОГИЧЕСКИХ ОБСТАНОВОК В КРИОЛИТОЗОНЕ (НА ПРИМЕРЕ ЯКУТИИ)

'Поморцева А.А., ${ }^{2}$ Поморцев О.А.

${ }^{\prime}$ ФГБОУ ВО «Санкт-Петербургский горный университет», Санкт-Петербург, e-mail: a.a.pomortseva@mail.ru;

${ }^{2}$ ФГАОУ ВО «Северо-Восточный федеральный университет имени М.К. Аммосова», Якутск

\begin{abstract}
На примере природных комплексов криолитозоны Якутии рассматривается проблема солнечного управления динамикой природно-климатических и инженерно-геологических обстановок и их аномалиями. Методами математического моделирования: Фурье- и вейвлет-анализа, автокорреляции и графического анализа исследованы ряды многолетних значений среднегодовой температуры приземного воздуха и атмосферных осадков метеостанции Якутск и ряд солнечной активности в числах Вольфа. Выявлена устойчивая связь динамики метеорологических элементов и фактора солнечной активности более чем за столетие (продолжительность ряда инструментальных метеорологических наблюдений в Якутске 190 лет, непрерывные наблюдения - последние 134 года). Установлено, что линейные тренды чисел Вольфа и среднегодовой температуры и атмосферных осадков в Якутске положительны, однонаправлены и вполне сопоставимы. При этом все моды выявленные в динамике рядов метеорологических элементов метеостанции Якутск $(11,22,36$, 48, 72 лет) согласуются с хорошо известными солнечно-обусловленными осцилляциями Швабе-Вольфа, Хэла, Брикнера, двойной Брикнера и полувековой. В целом ряд чисел Вольфа показывает последовательное усиление динамики солнечной активности на протяжении последних трех сотен лет, что косвенно может свидетельствовать о присутствии в режиме солнечной деятельности сверхвекового цикла «подстилающего» вековые. Возможно, именно этим циклом и, определяется тенденция к развитию потепления, особенно ярко проявившаяся с окончанием Малой ледниковой эпохи (МЛЭ) начиная с первой трети ХIX века. Выявлено усиление динамики опасных гидрологических, пирологических, сейсмических, инженерно-геологических процессов и режима наледеобразования по ходу аномалий 11-летних солнечных циклов - максимумов и минимумов. Как и аномалии климата они развиваются на ветвях подъема и спада циклов в непосредственной близости от их реперных фаз (максимумов и минимумов). Результаты исследований могут быть использованы для разработки и уточнения долгосрочных географических и инженерно-геологических прогнозов.
\end{abstract}

Ключевые слова: криолитозона, климат, потепление климата, метеорологические элементы, солнечная активность, опасные природные и инженерно-геологиические процессы, прогноз

\title{
HELIOCYCLIC MODULATIONS OF THE VARIABILITY OF NATURAL-CLIMATIC AND ENGINEERING-GEOLOGICAL CONDITIONS IN THE CRYOLITHOZONE (ON THE EXAMPLE OF YAKUTIA)
}

\author{
${ }^{1}$ Pomortseva A.A., ${ }^{2}$ Pomortsev O.A. \\ ${ }^{\text {I} S a i n t-P e t e r s b u r g}$ Mining University, Saint Petersburg, e-mail: a.a.pomortseva@mail.ru; \\ ${ }^{2}$ North-Eastern Federal University after M.K. Ammosov, Yakutsk
}

\begin{abstract}
The problem of solar control over the dynamics of natural climatic and engineering geological settings and their anomalies is considered using the example of natural complexes in the cryolithic zone of Yakutia. By methods of mathematical modeling: Fourier and wavelet analysis, autocorrelation and graphical analysis, we investigated a series of multi-year values of mean annual temperature of surface air and precipitation at the Yakutsk meteorological station and a number of solar activity in the numbers of the Wolf. A stable connection between the dynamics of meteorological elements and the solar activity factor for more than a century has been revealed (the duration of a series of instrumental meteorological observations in Yakutsk is 190 years and continuous observations for the last 134 years). The linear trends of Wolf numbers and average annual temperature and precipitation in Yakutsk have been found to be positive, unidirectional and quite comparable. At the same time, all the trends identified in the dynamics of the series of meteorological elements of the Yakutsk meteorological station $(11,22,36,48$ 72 years) are consistent with the well-known solar-conditioned oscillations of Schwabe-Wolf, Hal, Brickner, Double Brickner and half a century. In general, a number of Wolf numbers show a consistent increase in the dynamics of solar activity over the last three hundred years, which may indirectly indicate the presence in the solar regime of a super-centuries-old «substrate» cycle. Perhaps it is this cycle that determines the warming trend, which has been particularly pronounced since the end of the Little Ice Age since the first third of the 19th century. Dynamics of dangerous hydrological, pyrological, seismic, engineering-geological processes and the regime of ice formation in the course of anomalies of 11-year solar cycles - maximums and minimums have been strengthened. Like climate anomalies, they develop on the branches of ascending and descending cycles in close proximity to their reference phases (maximums and minimums). Research results can be used to develop and refine long-term geographic and engineering geological forecasts.
\end{abstract}

Keywords: cryolithozone, climate, warming of climate, meteorological elements, solar activity, dangerous natural and engineering-geological processes, forecast

Криолитозоона Якутии занимает площадь более 3 млн км² на востоке Евразии. Ее строение и функционирование определя- ются прежде всего экстремальными показателями климата, а также присутствием природных льдов с их тенденциями к фазовым 
переходам. Неустойчивость и мобильность верхних горизонтов криолитозоны стимулирует развитие здесь опасных криогенных процессов, охватывающих большие массы вещества и энергии. Это иногда приводит к опасным и даже катастрофическим проявлениям, например, масштабное разрушение криолитозоны в Верхоянских горах (рис. 1) что, в условиях прогрессирующего потепления климата, создает реальные предпосылки к развитию в Якутии опасных и даже катастрофических процессов криогенного генезиса. Феерическая картина батагайского провала (рис. 1) наглядно демонстрирует, с одной стороны, поистине грандиозные масштабы потенциально опасной ледовой структуры криолитозоны, с другой, масштабы проблемы, с которой нам предстоит столкнуться в случае дальнейшей эскалации потепления.

Наряду с криогенными существуют и другие, не менее опасные процессы, в частности землетрясения, а также - модулируемые все теми же флуктуациями климата, лесные пожары с их постпожарной переработкой криогенного рельефа, наводнения, снежные лавины, паводковосклоновые проявления - оползни-сплывы, селевые выбросы, наледеобразования. Эти процессы уже сегодня способны влиять на состояние природных и природно-технических геосистем, а через них и на социальные процессы.

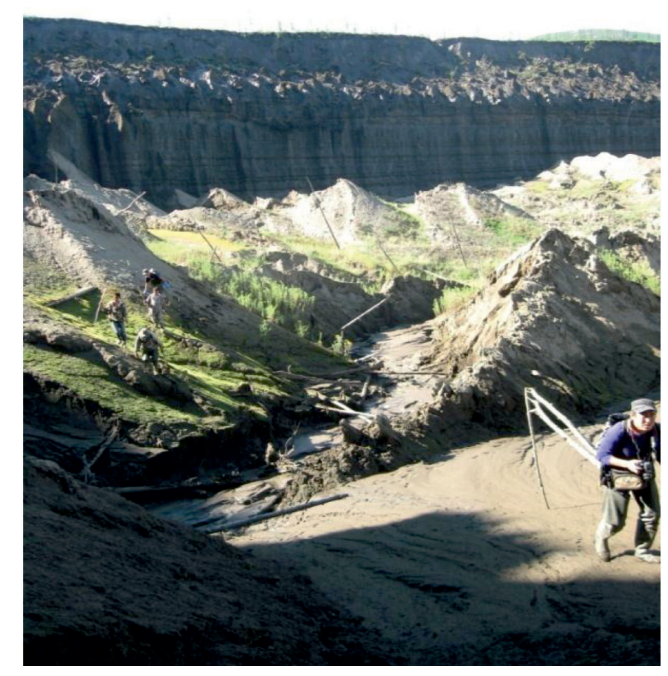

В современной волне глобального потепления, уже принёсшей ущерб человечеству на многие миллиарды долларов, установлены два непреложных факта:

1. Потепление идёт опережающими темпами на территории Якутии, расположенной в ядре Сибирского антициклона - главного холодильника Северного полушария;

2. Оно же представляет основную угрозу любым формам деятельности человека и его проживанию в зоне вечной мерзлоты, в которую опять же целиком входит Якутия.

Отсюда основной вывод: какие бы проблемы природного и социального характера мы не решали в Якутии, Северной Азии и Северном полушарии в целом, все они решаются только внутри проблемы глобального потепления.

Учитывая тот факт, что в настоящее время не существует не только ни одного надежно обоснованного прогноза о поведении многосотметровой толщи мерзлоты при развивающемся потеплении, но и надежного обоснования самого тренда потепления, рассматриваемая проблема обретает стратегическую направленность.

Цель исследования: поиск закономерностей в отклике климата, природных и инженерно-геологических процессов в криолитозоне Якутии на модуляции солнечной активности по ходу 11летнего и векового циклов.

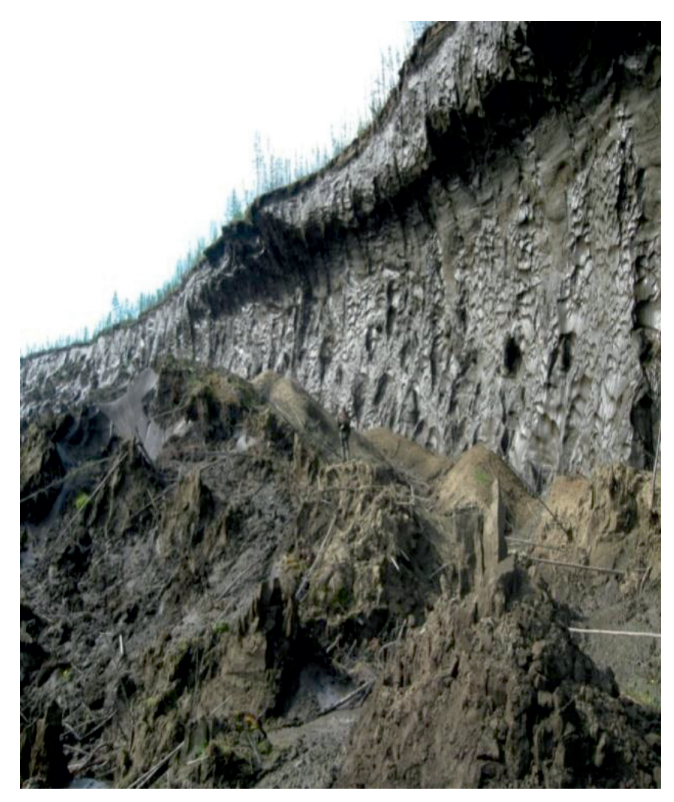

Рис. 1. Обнажившееся ледовое ядро криолитозоны в районе Батагайского касситеритового месторождения в долине речки Батагайки (фото П.П. Данилова) 


\section{Материалы и методы исследования}

Использовался комплекс методов математического моделирования: Фурье- и вейвлет анализа, автокорреляции и графического анализа численных рядов исходной метеорологической и гелиофизической информации, а также методы полевых геоморфологических и инженерно-геологических исследований природных и природно-технических геосистем криолитозны.

В качестве отправной точки для анализа закономерностей изменчивости природноклиматических обстановок в криолитозоне Якутии мы обратились к фактору солнечной активности (СА).

На первом этапе исследований методами численного моделирования: Фурье- и вейвлет-анализа, автокорреляции и графического анализа исследованы ряды многолетних значений среднегодовой температуры приземного воздуха и атмосферных осадков длиннорядной и репрезентативной метеостанции Якутск и ряд солнечной активности в числах Вольфа. Выявлена устойчивая связь динамики метеорологических элементов и фактора солнечной активности более чем за столетие (продолжительность ряда инструментальных метеорологических наблюдений в Якутске 190 лет, непрерывные наблюдения - последние 134 года).

По характеру отклонений в ходах кривой солнечной активности (рис. 2) отчетливо выделяются три вековые волны с периодом в 90-100 лет. В морфологии этих волн, как и по ходу 11-летних циклов, выделяются эпохи минимума, максимума и ветви подъема и спада. Установлено, что число короткоживущих групп солнечных пятен максимально в эпоху минимума векового цикла, тогда как самые долгоживущие и крупные группы чаще всего появляются в эпоху максимума [1].

К настоящему времени выполнены реконструкции гелиосферного модуляционного потенциала и чисел Вольфа на основе радиоуглеродных данных с начала XI века по середину XIX века с учетом климатических изменений [2]. Развитие солнечной активности по ходу 11-летнего цикла имеет свои особенности. На фазе роста цикла наблюдается быстрое увеличение активности, а на фазе спада - медленное затухание. При этом активность на фазе роста увеличивается тем быстрее, чем мощнее цикл (правило Вальдмайера), а на фазе спада её поведение хорошо связано с текущей средней широтой пятен [3].

А.Л. Чижевский [4] одним из первых показал глубокую зависимость процессов и явлений в географической оболочке от фактора солнечной активности. Наши исследования отклика рядов среднегодовой температуры и атмосферных осадков ГМС Якутск на 11-летний и вековой циклы СА показали, что наиболее значимые аномалии температуры и атмосферного увлажнения возникают на ветвях подъема и спада этих циклов тяготея к экстремумам в активности Солнца - максимумам и минимумам [5]. В целом ряд СА показывает последовательное усиление динамики на протяжении последних трех сотен лет, что косвенно может свидетельствовать о присутствии в режиме СА сверхвекового цикла «подстилающего» вековые (рис. 2). Очевидно, этим циклом и определяется тенденция к развитию потепления, особенно ярко проявившегося с окончанием Малой ледниковой эпохи (МЛЭ) в первой трети X1X века (рис. 3).

\section{Числа Вольфа}

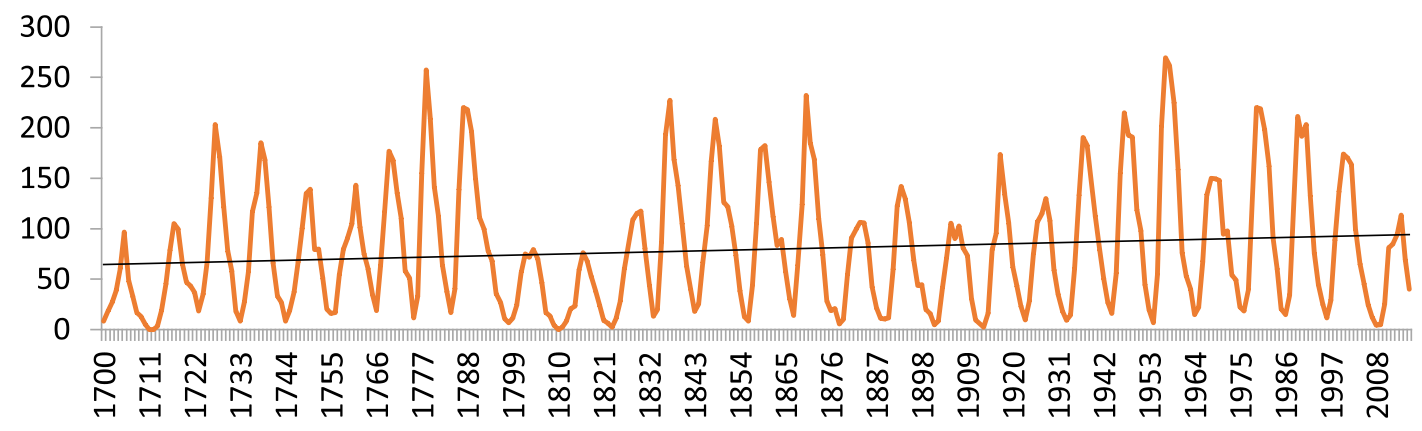

Рис. 2. Кривая солнечной активности в числах Вольфа (данные инструментальных телескопических наблюдений 1749-2017 г2. и рассчитаннье - 1700-1748 г2.) и ее линейньй тренд 


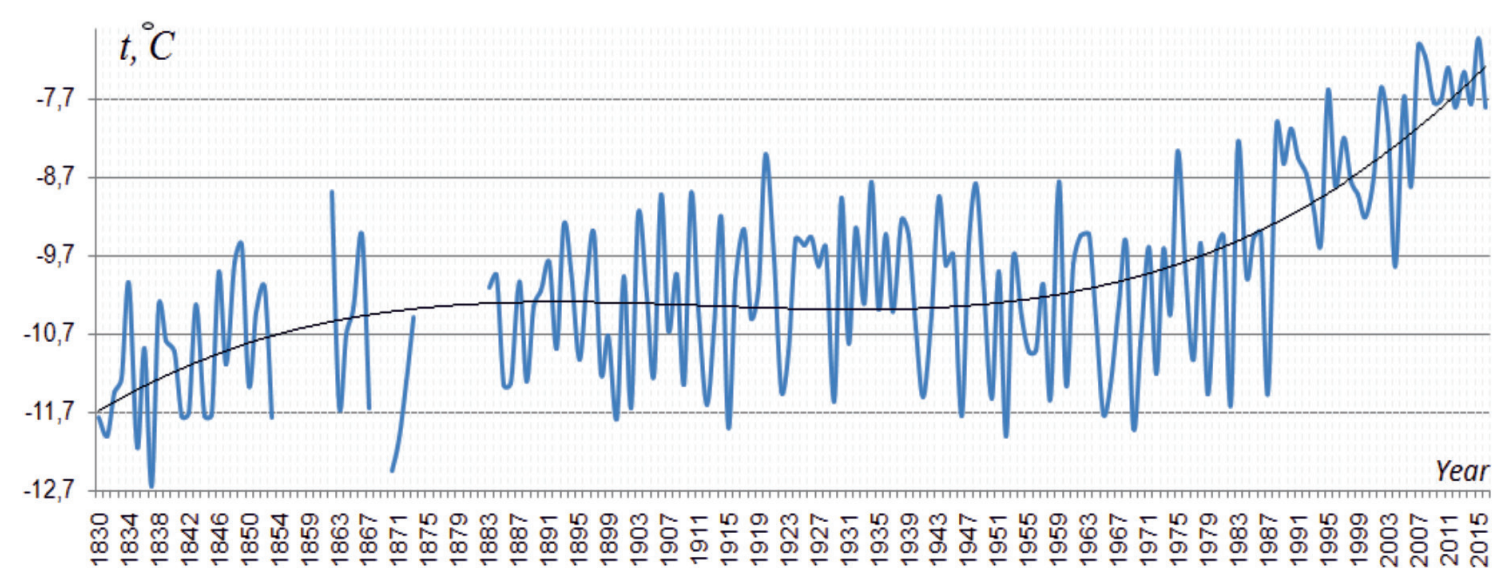

Рис. 3. Диограмма среднегодовой температуры г.Якутска с 1830 по 2016 гг.

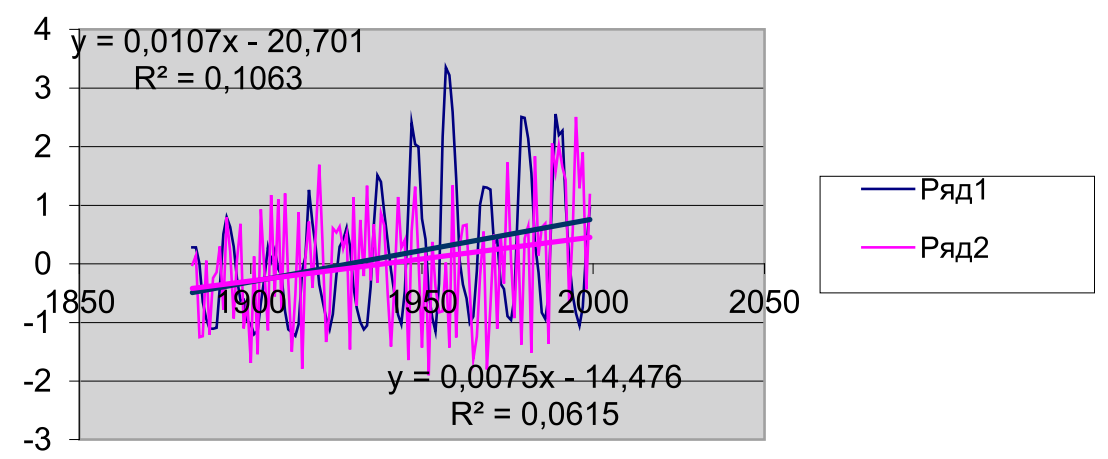

Рис. 4. Линейные тренды значений показателей среднегодовой температуры по ряду ГМС Якутск за период с 1883 г. по 2000 г. (ряд 2) и чисел Вольфа (ряд 1)

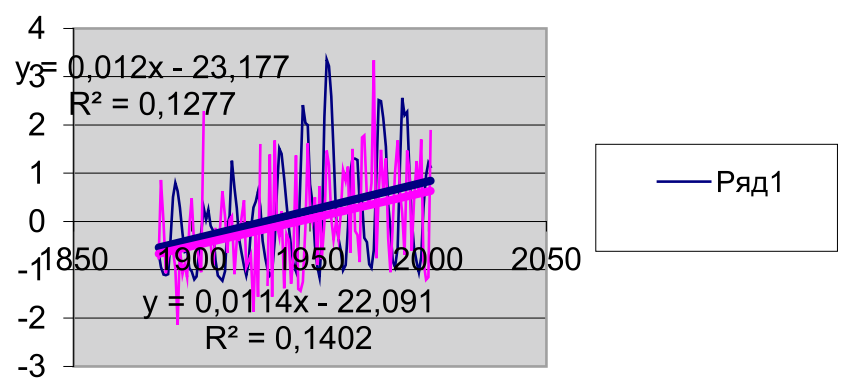

Рис. 5. Линейные тренды значений среднегодовых атмосферных осадков по ряду ГМС Якутск за период с 1883 г. по 2000 г. (ряд 2) и чисел Вольфа (ряд 1)

Из диаграмм рис. 4 и 5 видно, что линейные тренды чисел Вольфа и среднегодовой температуры и атмосферных осадков в Якутске положительны, однонаправлены и вполне сопоставимы. Ранее об климатических эффектах на десятилетних-столетних солнечных шкалах было показано в работах [6-7].

\section{Результаты исследования и их обсуждение}

На рис. 6 показано результаты Фурьеанализа ряда среднегодовой температуры метеостанции Якутск в сопоставлении с ходами СА в числах Вольфа (W).

Все моды, выявленные в динамике рядов метеорологических элементов мете- 
останции Якутск (11, 22, 36, 48, 72 лет), согласуются с хорошо известными солнечно-обусловленными осцилляциями Швабе-Вольфа, Хэла, Брикнера, двойной Брикнера и полувековой. При этом установлено запаздывание на 1/4 периода экстремумов циклов температуры (максимумов и минимумов) относительно экстремумов 11-летних циклов (рис. 6), что необходимо учитывать при прогнозировании климатических аномалий. в дальнейшем, сменившая влажную фазу сухая климатическая фаза проявилась синфазно максимуму четного 11-летнего цикла 18 , т.е. зеркально относительно влажной аномалии пришедшейся на максимум цикла 17. Следующая влажная аномалия проявилась на ветви спада четного цикла 18 вблизи минимума цикла 19, а последовавшая за ней сухая фаза - в начале ветви спада цикла 19 сразу за его максимумом. На ветви спада вековой волны СА ХХ столе-

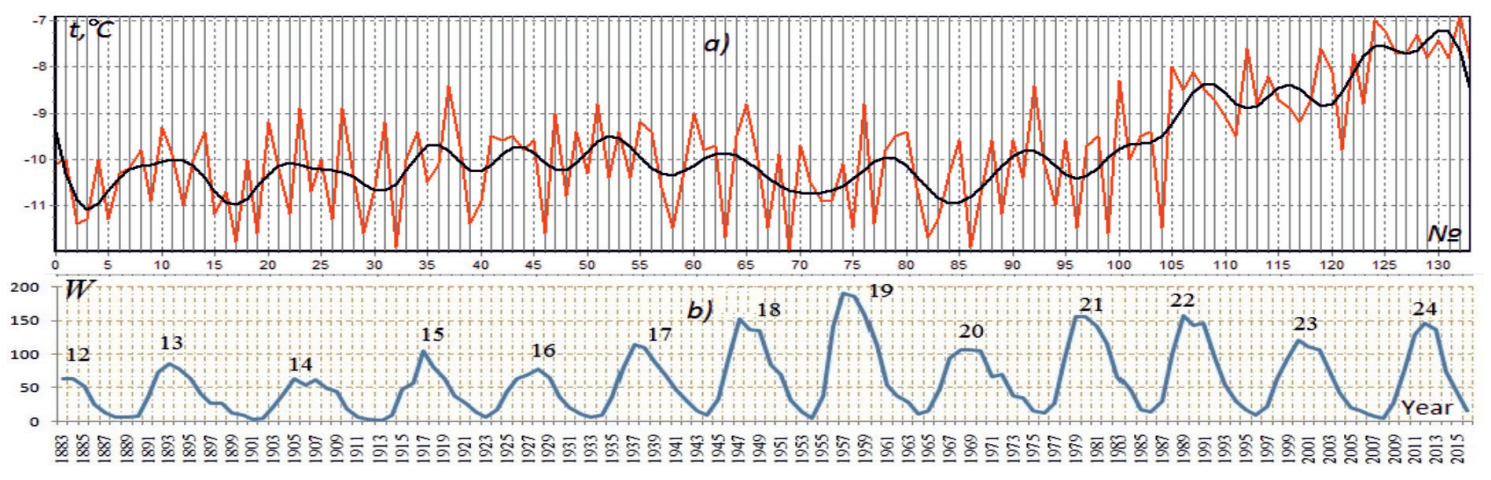

Рис. 6. Кривая среднегодовой температуры воздуха г. Якутска с гармониками Фурье-анализа (a) в прямом сопоставлении с графиком чисел Вольфа $(W)$, характеризующим солнечную активность (b). Арабскими циифрами на кривой W даны номера 11-летних цикллов

Анализ отклика атмосферного увлажнения на аномалии 11-летнего цикла показал, что за последние 87 лет непрерывных наблюдений на ГМС Якутск за атмосферными осадками (с 1934 по 2018 гг.) проявилось 11 волн (ритмов) усиления и ослабления их динамики периодически менявшие природно-климатические обстановки от менее аридных к более сухим, и наоборот. Аномалии увлажнения развивались на фоне реализации восьми 11-летних циклов солнечной активности проявившихся за тот же период времени (Циклы 17-24). Из них три цикла $-17,18$ и 19 приурочены к ветви подъема векового цикла СА прошлого столетия, а четыре - 20, 21, 22 и 23, к ветви его спада. Еще один цикл - 24-й относится к новому вековому циклу текущего века (см. рис. 6 b).

Первый максимум атмосферного увлажнения на шкале осадков проявился в Якутске в 1930-е гг. Он синфазен максимуму нечетного 11-летнего цикла 17. Однако последовавший за ним минимум осадков проявился не на минимуме солнечного цикла, а ранее - на ветви спада цикла 17, причем, последовавшая затем положительная аномалия увлажнения пришлась на минимум следующего четного цикла 18. Кроме того, тия (циклы 20, 21, 22 и 23) и в начале ветви подъема нового векового цикла (11-летний цикл 24) положительные аномалии осадков тяготеют к максимумам нечетных и к минимумам четных 11-летних циклов, тогда как отрицательные аномалии или засухи, наоборот - к минимумам нечетных и максимумам четных.

Таким образом, можно заключить, что несмотря на определенную «турбулентность» проявившуюся в ходах кривой атмосферных осадков на фоне векового усиления солнечной активности по ходу ветви подъема векового цикла прошлого столетия, достаточно отчетливо просматривается закономерность состоящая в том, что аномалии осадков, тяготеют к реперным фазам 11-летних циклов - их максимумам и минимумам. В шести последних циклах максимумам нечетных циклов и минимумам четных соответствуют положительные аномалии осадков, тогда как отрицательные или засухи пришлись на минимумы нечетных и максимумы четных. Выявленную закономерность вероятно можно объяснить наличием разной магнитной полярности у четного и нечетного 11-летних циклов (закон Хэла). 
Статистический анализ аномалий гидрологических, пирологических, сейсмических, инженерно-геологических процессов и режима наледеобразования показал, что развитие всех изученных природных аномалий, в том числе и опасных, сопряжено с аномалиями СА. Как правило, аномалии исследованных природных процессов, как и аномалии климата, развиваются на ветвях подъема и спада солнечных циклов в непосредственной близости от их реперных фаз - максимумов и минимумов [8-10].

\section{Заключение}

Анализ результатов проделанной работы не оставляет сомнений в том, что динамика природно-климатических процессов в криолитозне Якутии, как и опасные инженерно-геологические обстановки на участках горно-геологического освоения модулируются циклами солнечной активности. Они тяготеют к реперным фазам циклов максимумам и минимумам.

В целом результаты выполненных исследований указывают на то, что в нашем распоряжении появилась космическая гелиогеофизическая матрица, которую можно использовать при разработке и уточнении долгосрочных географических и инженерно-геологических прогнозов в Якутии.

\section{Список литературы / References}

1. Витинский Ю.К. Цикличность и прогнозы солнечной активности. Л.: Наука, 1973. 257 с.

Vitinsky Yu.K. Cyclicity and forecasts of solar activity. L.: Nauka, 1973. 257 p. (in Russian).

2. Кулешова А.И., Дергачев В.А., Кудрявцев И.В., Наговицын Ю.А., Огурцов М.Г. Реконструкция гелиосферного модуляционного потенциала и чисел Вольфа на основе радиоуглеродных данных с начала 11 века по середину 19 века с учетом климатических изменений // Солнечная и солнечно-земная физика: труды XXI Всероссийской ежегодной конференции по физике Солнца. СПб., 2017. С. 215-218.

Kuleshova A.I., Dergachev V.A., Kudryavtsev I.V., Nagovitsyn Yu.A., Ogurtsov M.G. Reconstruction of the heliospheric modulation index and Wolf numbers based on radiocarbon data from with the beginning of the 11th century to the middle of the 19th century taking into account climatic changes // Solnech- naya i solnechno-zemnaya fizika: trudy KHKHI Vserossiyskoy yezhegodnoy konferentsii po fizike Solntsa. SPb., 2017. P. 215218 (in Russian).

3. Ivanov V.G., Miletsky E.V. Spörer's law and relationship between the latitude and amplitude parameters of solar activity. Geomagnetism and Aeronomy. 2014. V. 54. P. 907-914.

4. Чижевский А.Л. Земное эхо солнечных бурь. М., 1976. $349 \mathrm{c}$

Chizhevsky A.L. Earth echo of solar storms. M., 1976. 349 p. (in Russian).

5. Trofimtsev Y.I., Pomortsev O.A., Popov V.F., Pomortseva A.A. Numerical modeling of harmonics in meteorological time series. Citation: AIP Conference Proceedings. 2017. V. 1907. P. 030025. DOI: 10.1063/1.5012647.

6. Семачкина Ю.С. Солнечная активность. Солнечноземные связи // Молодежь и наука: сборник материалов IX Всероссийской научно-технической конференции студентов, аспирантов и молодых ученых с международным участием, посвященной 385-летию со дня основания г. Красноярска. [Электронный ресурс]. URL: http://conf.sfu-kras.ru/ sites/mn2013/section112.html (дата обращения: 12.12.2020).

Semachkina Yu.S. Solar Activity. Solar-terrestrial connections // Molodezh' i nauka: sbornik materialov IKH Vserossiyskoy nauchno-tekhnicheskoy konferentsii studentov, aspirantov i molodykh uchenykh s mezhdunarodnym uchastiyem, posvyashchennoy 385-letiyu so dnya osnovaniya g. Krasnoyarska. [Electronic resource]. URL: http://conf.sfu-kras.ru/sites/mn2013/section112.html (date of access: 12.12.2020) (in Russian).

7. Дергачев В.А. Изменение солнечной радиации и климатические эффекты на десятилетних-столетних солнечных шкалах // Солнечная и Солнечно-Земная физика: труды XXI Всероссийской ежегодной конференции по физике Солнца. СПб., 2017. С. 135-140.

Dergachev V.A. Changes in solar radiation and climatic effects on decadal-centennial solar scale// Solnechnaya i Solnechno-Zemnaya fizika: trudy KHKHI Vserossiyskoy yezhegodnoy konferentsii po fizike Solntsa. SPb., 2017. P. 135140 (in Russian).

8. Поморцев О.А. Попов В.Ф., Рожин С.С. Землетрясения: ритмические основы долгосрочного прогноза (на примере Якутии) // Отечественная геология. 2011. № 6. С. 33-38.

Pomortsev O.A. Popov V.F., Rozhin S.S. Earthquakes: Rhythmic Foundations of Long-Term Forecast (on the Example of Yakutia) // Otechestvennaya Geologiya. 2011. No. 6. P. 3338 (in Russian).

9. Pomortsev O.A., Pomortseva A.A.Cyclic Organization of Geological Environment: Permafrost Zone of Yakutia. IOP Conf. Series: Earth and Environmental Science. 2019. V. 272. P. 022059. DOI: $10.1088 / 1755-1315 / 272 / 2 / 022059$.

10. Леви К.Г., Язев С.А., Задонина Н.В., Бердникова Н.Е., Воронин В.И., Глызин А.В., Кушнер Ю.С. Современная геодинамика и гелиогеодинамика. Иркутск, 2002. 182 с.

Levi K.G., Yazev S.A., Zadonina N.V., Berdnikova N.E., Voronin V.I., Glyzin A.V., Kushner Yu.S. Modern geodynamics and heliogeodynamics. Irkutsk, 2002. 182 p. (in Russian). 